International Journal of Performability Engineering, Vol. 13, No. 1, January 2017, pp. 63-72

(C) Totem Publisher, Inc., 4625 Stargazer Dr., Plano,

Printed in U.S.A

\title{
Stochastic and Cost-Benefit Analysis of Two Unit Hot Standby Database System
}

\author{
AMIT MANOCHA ${ }^{1}$, GULSHAN TANEJA ${ }^{2}$ and SUKHVIR SINGH ${ }^{3}$ \\ ${ }^{1}$ Department of Mathematics, T.I.T. S., Bhiwani, Haryana, India \\ ${ }^{2}$ Department of Mathematics, M.D. University Rohtak, Haryana, India \\ ${ }^{3}$ Department of Computer Science, N.C.C.E. Panipat, Haryana, India
}

(Received on October 08, 2016, revised on November 30, 2016)

\begin{abstract}
A discrete state space and continuous time stochastic model for two unit hot standby database system has been developed. The system comprised of one primary unit and single hot standby unit. The primary unit is production unit synchronized with hot standby unit through online transfer of archive redo log files. Different modes of failure of primary database unit are considered. Failure of database unit either primary or standby is dealt by database administrator (DBA). Expressions for various measures of system effectiveness have been obtained by making use of semi-Markov processes and regenerative point technique. Numerical results have been drawn on the basis of data collected. Bounds pertaining the profitability of the system have also been obtained.
\end{abstract}

Keywords: Database system, hot standby, semi-Markov process, cost-benefit analysis, regenerative point technique

\section{Introduction}

Database system plays a pivotal role locally or globally in handling and securing data for various industries. Promising technological advancements have made enterprises absolutely dependent on automated database systems. A small operational error in these systems may lead to disastrous failures which differ in the severity of their impact depending on the operations of an organization. Few major database system provider companies to mention are Oracle corporation provides RDBMS Oracle and open source DBMS MySQL; Microsoft Corporation provides Microsoft Access and Microsoft SQL Server; IBM provides DB2.Depending upon the volume of company and significance of the data primary database unit and number of standby units are provided by the companies. Such systems maintain the data for various industries working globally in Telecommunication, Automobile, Gas \& Oil, Transportation, Education, Medical, Finance, Marketing, Banking, Textile and Garments sectors, etc. Keeping that in view, reliability and availability analysis of these automated database systems is of great importance in the present scenario. The present paper is our attempt to analyze a two unit hot standby database system.

Standby systems have been discussed extensively by various researchers including [1-3]. Beith et al. [4] discussed a two-identical-cold standby system with two types of 
repair persons under arbitrary life and repair times. Shakuntla et al. [5] did the reliability analysis of polytube industry by using supplementary variable technique. Reliability analysis of a seven unit desalination plant with shutdown during winter season and repair/maintenance on FCFS basis was carried out by Rizwan et al. [6]. Manocha and Taneja [7] analyzed a stochastic model for two unit cold standby system with arbitrary distribution for life, repair and waiting times. Kuo and $\mathrm{Ke}[8]$ did the comparative analysis of standby systems with unreliable server and switching failures. Kumar and Batra [9] developed a stochastic model for printed circuit boards (PCBs) manufacturing process.

Singh et al. [10] did the reliability and availability analysis of database system with numbers of standby units provided by system provider. Higher number of standby units eventually may lead to increased cost, which is to be paid by the user itself. Two unit hot standby database system has not being discussed so far in the literature. So, the present study deals with database system comprising of one primary production database unit synchronized with single hot standby unit through online transfer and simultaneous archiving redo logs.

\section{Notations}

$\lambda \quad$ constant failure rate of primary database unit

$\alpha \quad$ constant failure rate of standby database unit

$\mathrm{p}_{1} \quad$ probability that standby unit is in synchronous with primary database unit on the failure of primary database unit

$\mathrm{p}_{2} \quad$ probability that redo log files are not updated in standby database unit on the failure of primary database unit

$\mathrm{p}_{3} \quad$ probability that redo log files are not created in standby database unit on the failure of primary database unit

$\mathrm{M}_{\mathrm{i}}(\mathrm{t}) \quad$ probability that primary database unit up initially in regenerative state $\mathrm{i}$ is up at time $t$ without passing through any other regenerative state or returning to itself through one or more non-regenerative states

$\mathrm{g}(\mathrm{t}) / \mathrm{G}(\mathrm{t}) \quad \mathrm{pdf} / \mathrm{cdf}$ of the time for repairing the primary database unit

$\mathrm{g}_{1}(\mathrm{t}) / \mathrm{G}_{1}(\mathrm{t}) \quad \mathrm{pdf} / \mathrm{cdf}$ of the time for repairing the standby database unit

$\mathrm{h}_{1}(\mathrm{t}) / \mathrm{H}_{1}(\mathrm{t}) \quad \mathrm{pdf} / \mathrm{cdf}$ of the time for updating the redo log files in the standby database unit

$\mathrm{h}_{2}(\mathrm{t}) / \mathrm{H}_{2}(\mathrm{t}) \quad \mathrm{pdf} / \mathrm{cdf}$ of the time for creating the redo log files in the standby database unit

(R/C $\quad$ symbol for Laplace-Stieljes convolution / Laplace convolution

for some standard notations one may refer to [2].

Let us now describe the system considered for modelling along with the assumptions taken for developing the same.

\section{System Description and Assumptions}

Figure 1 demonstrates the functioning of two unit hot standby database system. The standby database unit is kept in synchronization with primary database unit through online redo $\log$ files. Redo log files created at primary site are archived at the standby site. In case of the failure of primary unit the standby unit becomes the production unit and the failed unit goes under repair of database administrator (DBA) immediately.

The following situations, which are mutually exclusive and exhaustive, may be observed on the failure of primary unit: 
i. Standby unit working in synchronous with primary unit

ii. Redo log files are not updated in standby unit

iii. Redo log files are not created in standby unit

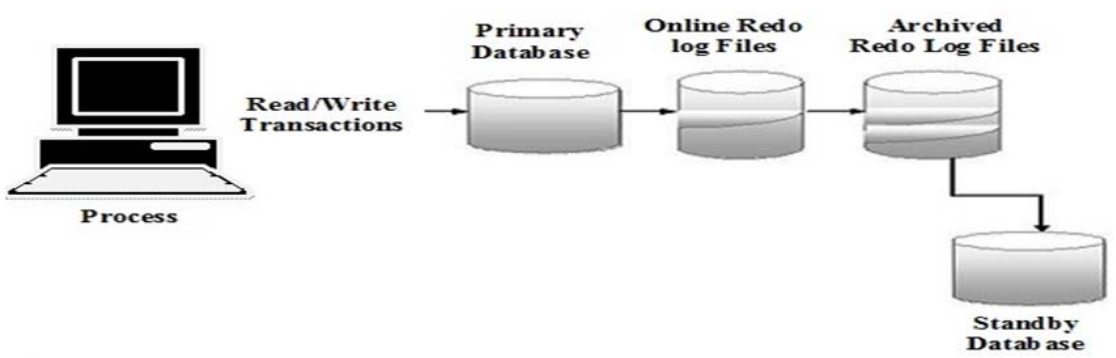

Figure 1: Two Unit Hot Standby Database System

In the situational failure of primary unit all the archived redo log files are updated/created into standby unit by the DBA, before making it production database. Cost for using standby database unit as the primary database unit is to be paid by user itself. Proposed system has a single DBA facility. After each repair, the system works as good as new. All failure times are assumed to have exponential distribution whereas repair times, time for creating and updating redo log files have general distributions. By using semi-Markov process and regenerative point technique expressions for various measures of system effectiveness such as Mean time to system failure, Mean time to failure of primary database unit, Availability of primary database unit, busy period of DBA, Expected number of visits by the DBA and profit function has obtained. Numerical analysis has been done on the basis of data collected for database systems. Bounds concerning the profitability of the system have also been obtained.

All the possibilities have been shown by states and transitions from one state to another along with transition probabilities and mean sojourn times in the following section.

\section{Modelling of the System}

Symbols for the states of the system are

$\mathrm{P}_{0} \quad$ primary database unit is operative

$\mathrm{H}_{\mathrm{s}} / \mathrm{H}_{\mathrm{r}} / \mathrm{H}_{\mathrm{R}} \quad$ hot standby database/under repair/repair from previous state

$\mathrm{S}_{0} \quad$ hot standby database unit is used as primary database unit

$\mathrm{S}_{\mathrm{r}} / \mathrm{S}_{\mathrm{w}} / \mathrm{S}_{\mathrm{R}} \quad$ hot standby unit (used as primary database unit) is under repair/waiting

for repair/ repair from previous state

$\mathrm{F}_{\mathrm{r}} / \mathrm{F}_{\mathrm{w}} / \mathrm{F}_{\mathrm{R}} \quad$ failed unit under repair / waiting for repair / repair from previous state

$\mathrm{P}_{\mathrm{f}} \mathrm{H}_{\mathrm{S}} \mathrm{A} \overline{\mathrm{D}} \quad$ primary database unit fails and redo log files are not updated in hot standby database

$\mathrm{P}_{\mathrm{f}} \mathrm{H}_{\mathrm{S}} \overline{\mathrm{A}} \quad$ primary database unit fails and redo log files are not created in hot standby database unit

Considering these symbols, the system can be in any one of the following states

State 0: $\left(\mathrm{P}_{0}, \mathrm{H}_{\mathrm{S}}\right) \quad$ State 1: $\left(\mathrm{F}_{\mathrm{r}}, \mathrm{S}_{0}\right) \quad$ State 2: $\left(\mathrm{P}_{0}, \mathrm{H}_{\mathrm{r}}\right)$ State 3: $\left(\mathrm{F}_{\mathrm{w}}, \mathrm{H}_{\mathrm{R}}\right)$

State 4: $\left(\mathrm{P}_{\mathrm{f}} \mathrm{H}_{\mathrm{S}} \mathrm{AD}\right)$ State 5: $\left(\mathrm{P}_{\mathrm{f}} \mathrm{H}_{\mathrm{S}} \overline{\mathrm{A}}\right)$ State 6: $\left(\mathrm{F}_{\mathrm{R}}, \mathrm{S}_{\mathrm{w}}\right)$ State 7: $\left(\mathrm{P}_{0}, \mathrm{~S}_{\mathrm{r}}\right)$ State 8: $\left(\mathrm{F}_{\mathrm{w}}, \mathrm{S}_{\mathrm{R}}\right)$

Possible transitions of the system are shown in Figure 2: 


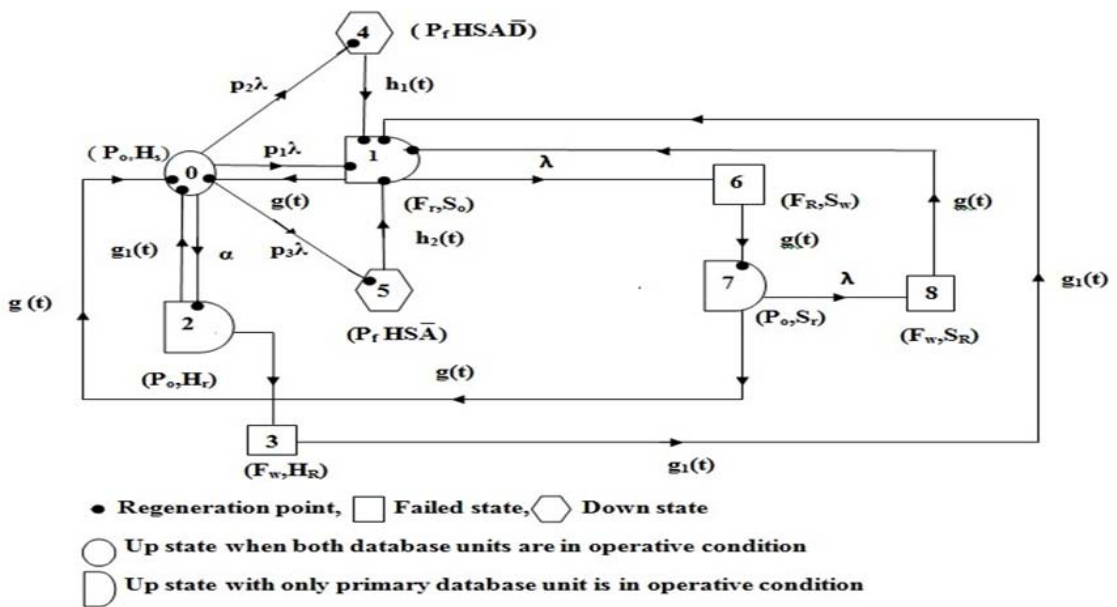

Figure 2: State Transition

Here $E=\{0,1,2,4,5,7\}$ is set of regenerative states and $\bar{E}=\{3,6,8\}$ is a set of nonregenerative states. States 3,6 and 8 are failed states, whereas 4 and 5 are down states Let $_{0}(\equiv 0), T_{1}, T_{2},-----$ be the epochs at which system enters to any state $i \in E$ and let $X_{n}$ be the state visited at epoch in $T_{n+1}$ i.e. just after transition at $T_{n}$. Then $\left\{X_{n}, T_{n}\right\}$ is a Markov-renewal process with state space $\mathrm{E}$.Let

$$
\mathrm{q}_{\mathrm{ij}}=\mathrm{P}\left\{\mathrm{X}_{\mathrm{n}+1}=\mathrm{j}, \mathrm{T}_{\mathrm{n}+1}-\mathrm{T}_{\mathrm{n}} \leq \mathrm{t} \mid \mathrm{X}_{\mathrm{n}}=\mathrm{i}\right\}
$$

be the semi-Markov kernel over E. The transition probability matrix (t.p.m.) of the embedded Markov chain is, therefore, given by

where

$$
P=\left(p_{i j}\right)=\left[q_{i j}(\infty)=q(\infty)\right]
$$

$$
\begin{aligned}
& \mathrm{p}_{01}=\int_{0}^{\infty} \mathrm{p}_{1} \lambda \mathrm{e}^{-(\lambda+\alpha) \mathrm{t}} \mathrm{dt}, \quad \mathrm{p}_{02}=\int_{0}^{\infty} \alpha \mathrm{e}^{-(\lambda+\alpha) \mathrm{t}} \mathrm{dt}, \quad \mathrm{p}_{04}=\int_{0}^{\infty} \mathrm{p}_{2} \lambda \mathrm{e}^{-(\lambda+\alpha) \mathrm{t}} \mathrm{dt}, \\
& \mathrm{p}_{05}=\int_{0}^{\infty} \mathrm{p}_{3} \lambda \mathrm{e}^{-(\lambda+\alpha) \mathrm{t}} \mathrm{dt}, \quad \mathrm{p}_{10}=\int_{0}^{\infty} \mathrm{e}^{-\lambda \mathrm{t}} \mathrm{g}(\mathrm{t}) \mathrm{dt}, \quad \mathrm{p}_{20}=\int_{0}^{\infty} \mathrm{e}^{-\lambda \mathrm{t}} \mathrm{g}_{1}(\mathrm{t}) \mathrm{dt} \\
& \mathrm{p}_{23}=\int_{0}^{\infty} \lambda \mathrm{e}^{-\lambda \mathrm{t}} \overline{\mathrm{G}_{1}}(\mathrm{t}) \mathrm{dt}, \quad \mathrm{p}_{41}=\int_{0}^{\infty} \mathrm{h}_{1}(\mathrm{t}) \mathrm{dt}, \quad \mathrm{p}_{51}=\int_{0}^{\infty} \mathrm{h}_{2}(\mathrm{t}) \mathrm{dt}, \\
& \mathrm{p}_{70}=\int_{0}^{\infty} \mathrm{e}^{-\lambda \mathrm{t}} \mathrm{g}(\mathrm{t}) \mathrm{dt}, \quad \mathrm{p}_{16}=\mathrm{p}_{78}=\int_{0}^{\infty} \lambda \mathrm{e}^{-\lambda \mathrm{t}} \overline{\mathrm{G}}(\mathrm{t}) \mathrm{dt}, \\
& \mathrm{p}_{21}^{(3)}=\int_{0}^{\infty}\left(\lambda \mathrm{e}^{-\lambda \mathrm{t}}(\mathrm{C}) \mathrm{g}_{1}(\mathrm{t}) \mathrm{dt}, \quad \mathrm{p}_{17}^{(6)}=\mathrm{p}_{71}^{(8)}=\int_{0}^{\infty}\left(\lambda \mathrm{e}^{-\lambda \mathrm{t}}(\mathrm{C} 1) \mathrm{g}(\mathrm{t}) \mathrm{dt}\right. \text {. }\right. \\
& \begin{array}{llll}
\mathrm{p}_{01}+\mathrm{p}_{02}+\mathrm{p}_{04}+\mathrm{p}_{05}=1, & \mathrm{p}_{10}+\mathrm{p}_{16}=1, & \mathrm{p}_{10}+\mathrm{p}_{17}^{(6)}=1, & \mathrm{p}_{20}+\mathrm{p}_{23}=1, \\
\mathrm{p}_{20}+\mathrm{p}_{21}^{(3)}=1, & \mathrm{p}_{70}+\mathrm{p}_{78}=1, & \mathrm{p}_{41}=\mathrm{p}_{51}=1, & \mathrm{p}_{70}+\mathrm{p}_{71}^{(8)}=1
\end{array}
\end{aligned}
$$

Mean Sojourn time $\left(\mu_{\mathrm{i}}\right)$ in regenerative state $\mathrm{i} \in \mathrm{E}$, is given as

$\begin{array}{llrl}\mu_{0}=\int_{0}^{\infty} \mathrm{e}^{-(\lambda+\alpha) t} \mathrm{dt}, & \mu_{1}=\mu_{7}=\int_{0}^{\infty} \mathrm{e}^{-\lambda \mathrm{t}} \overline{\mathrm{G}}(\mathrm{t}) \mathrm{dt}, & \mu_{2}=\int_{0}^{\infty} \mathrm{e}^{-\lambda \mathrm{t}} \overline{\mathrm{G}_{1}}(\mathrm{t}) \mathrm{dt}, \\ \mu_{4}=\int_{0}^{\infty} \overline{\mathrm{H}_{1}}(\mathrm{t}) \mathrm{dt} & \mu_{5}=\int_{0}^{\infty} \overline{\mathrm{H}_{2}}(\mathrm{t}) \mathrm{dt} & \text { (24-28) }\end{array}$

The unconditional time taken by system to transit for any regenerative state $\mathrm{j}$ when it (time) is counted from the epoch of entrance into state $\mathrm{i}$ is given as

$\mathrm{m}_{01}+\mathrm{m}_{02}+\mathrm{m}_{04}+\mathrm{m}_{05}=\mu_{0,} \quad \mathrm{~m}_{10}+\mathrm{m}_{16}=\mu_{1}, \quad \mathrm{~m}_{20}+\mathrm{m}_{23}=\mu_{2}, \quad \mathrm{~m}_{70}+\mathrm{m}_{78}=\mu_{7}$,

$\mathrm{m}_{41}=\mu_{4}, \quad \mathrm{~m}_{51}=\mu_{5}$,

$\mathrm{m}_{10}+\mathrm{m}_{17}^{(6)}=\mathrm{m}_{70}+\mathrm{m}_{71}^{(8)}=-\mathrm{g}^{* \prime}(0)=\mathrm{K}_{1}$ (say),

$\mathrm{m}_{20}+\mathrm{m}_{21}^{(3)}=-\mathrm{g}_{1}{ }^{* \prime}(0)=\mathrm{K}_{2}$ (say). 
Now, to find the reliability and to give cost-benefit analysis, various measures of system effectiveness are required to be obtained. The succeeding section determines all such measures.

\section{Measures of System Effectiveness}

\subsection{Mean Time to System Failure (MTSF)}

To determine mean time to system failure (MTSF) we regard the failed state as absorbing state. Let $\pi_{i}(t)$, where $i \in E$, be c.d.f. of the first passage time from regenerative state $i$ to a failed state, employing the arguments used for regenerative process, we have the following recursive relations for ' $\pi_{i}(t)$ '

$\pi_{0}(\mathrm{t})=\mathrm{Q}_{01}(\mathrm{t}){ }^{\circledR} \pi_{1}(\mathrm{t})+\mathrm{Q}_{02}(\mathrm{t}) \circledR \pi_{2}(\mathrm{t})+\mathrm{Q}_{04}(\mathrm{t}) \circledR \pi_{4}(\mathrm{t})+\mathrm{Q}_{05}(\mathrm{t}){ }^{\circledR} \pi_{5}(\mathrm{t})$

$\pi_{1}(\mathrm{t})=\mathrm{Q}_{16}(\mathrm{t})+\mathrm{Q}_{10}(\mathrm{t}) \circledast \pi_{0}(\mathrm{t})$

$\pi_{2}(\mathrm{t})=\mathrm{Q}_{23}(\mathrm{t})+\mathrm{Q}_{20}(\mathrm{t}) \mathbb{R} \pi_{0}(\mathrm{t})$

$\pi_{4}(\mathrm{t})=\mathrm{Q}_{41}(\mathrm{t}) \mathbb{B} \pi_{1}(\mathrm{t})$

$\pi_{5}(\mathrm{t})=\mathrm{Q}_{51}(\mathrm{t}) \mathbb{R} \pi_{1}(\mathrm{t})$

$\pi_{7}(\mathrm{t})=\mathrm{Q}_{78}(\mathrm{t})+\mathrm{Q}_{70}(\mathrm{t}){ }^{\circledR} \pi_{0}(\mathrm{t})$

Taking Laplace-Stieljes transformation of the above equations and solving them for $\pi_{0}{ }^{* *}(\mathrm{~s})$, We obtain $\pi_{0}{ }^{* *}(\mathrm{~s})=\mathrm{N}(\mathrm{s}) / \mathrm{D}(\mathrm{s})$

where, $\mathrm{N}(\mathrm{s})=\mathrm{Q}_{01}{ }^{* *}(\mathrm{~s}) \mathrm{Q}_{16}{ }^{* *}(\mathrm{~s})+\mathrm{Q}_{02}{ }^{* *}(\mathrm{~s}) \mathrm{Q}_{23}{ }^{* *}(\mathrm{~s})+\mathrm{Q}_{04}{ }^{* *}(\mathrm{~s}) \mathrm{Q}_{41}{ }^{* *}(\mathrm{~s}) \mathrm{Q}_{16}{ }^{* *}(\mathrm{~s})$ $+\mathrm{Q}_{05}{ }^{* *}(\mathrm{~s}) \mathrm{Q}_{51^{* *}}{ }^{* *}(\mathrm{~s}) \mathrm{Q}_{16}{ }^{* *}(\mathrm{~s})$

and $\mathrm{D}(\mathrm{s})=1-\mathrm{Q}_{01}{ }^{* *}(\mathrm{~s}) \mathrm{Q}_{10}{ }^{* *}(\mathrm{~s})-\mathrm{Q}_{02}{ }^{* * *}(\mathrm{~s}) \mathrm{Q}_{20}{ }^{* *}(\mathrm{~s})-\mathrm{Q}_{04}{ }^{* *}(\mathrm{~s}) \mathrm{Q}_{41}{ }^{* *}(\mathrm{~s}) \mathrm{Q}_{10}{ }^{* *}(\mathrm{~s})$ $-\mathrm{Q}_{05}{ }^{* *}(\mathrm{~s}) \mathrm{Q}_{51}{ }^{* *}(\mathrm{~s}) \mathrm{Q}_{10}{ }^{* *}(\mathrm{~s})$

The reliability of the system at time $t$ is given by,

$$
\mathrm{R}(\mathrm{t})=\mathrm{L}^{-1}\left[\left\{1-\pi_{0}^{* *}(\mathrm{~s})\right\} / \mathrm{s}\right]
$$

Now the mean time to system failure (MTSF) when the system starts from state ' 0 ' is

$$
\mathrm{MTSF}=\int_{0}^{\infty} \mathrm{R}(\mathrm{t}) \mathrm{dt}=\mathrm{N} / \mathrm{D}
$$

where, $N=\left\{\mu_{0}+\mu_{1}\left(p_{01}+p_{04}+p_{05}\right)+p_{02} \mu_{2}+p_{04} \mu_{4}+p_{05} \mu_{5}\right\}$

and $\quad \mathrm{D}=\left\{\mathrm{p}_{16}\left(\mathrm{p}_{01}+\mathrm{p}_{04}+\mathrm{p}_{05}\right)+\mathrm{p}_{02} \mathrm{p}_{23}\right\}$

\subsection{Mean Time to Failure of Primary Database Unit (MTFP)}

Let $\operatorname{TP}_{i}(t)$, where $i \in E$, be the c.d.f. of the first passage time of primary database unit from regenerative state $\mathrm{i}$ to the state where it is failed. By using arguments of theory of regenerative process, we have the following recursive relations for ' $\mathrm{TP}_{\mathrm{i}}(\mathrm{t})$ '

$\mathrm{TP}_{0}(\mathrm{t})=\mathrm{Q}_{01}(\mathrm{t})+\mathrm{Q}_{04}(\mathrm{t})+\mathrm{Q}_{05}(\mathrm{t})+\mathrm{Q}_{02}(\mathrm{t}){ }^{\mathbb{R}} \mathrm{TP}_{2}(\mathrm{t})$

$\mathrm{TP}_{2}(\mathrm{t})=\mathrm{Q}_{23}(\mathrm{t})+\mathrm{Q}_{20}(\mathrm{t}){ }^{\circledR} \mathrm{TP}_{0}(\mathrm{t})$

Taking Laplace-Stieljes transformation of above equations and solving them for $\operatorname{TP}_{0}^{* *}(\mathrm{~s})$, We obtain

$$
\mathrm{TP}_{0}^{* *}(\mathrm{~s})=\mathrm{N}_{1}(\mathrm{~s}) / \mathrm{D}_{1}(\mathrm{~s})
$$

where, $\mathrm{N}_{1}(\mathrm{~s})=\mathrm{Q}_{01}{ }^{* *}(\mathrm{~s})+\mathrm{Q}_{04}{ }^{* *}(\mathrm{~s})+\mathrm{Q}_{05}{ }^{* *}(\mathrm{~s})+\mathrm{Q}_{02}{ }^{* *}(\mathrm{~s}) \mathrm{Q}_{23}{ }^{* *}(\mathrm{~s})$

and $\mathrm{D}_{1}(\mathrm{~s})=1-\mathrm{Q}_{02}{ }^{* *}(\mathrm{~s}) \mathrm{Q}_{20}{ }^{* *}(\mathrm{~s})$

Now, the mean time to failure of primary database unit when the system start from state ' 0 ' is

where, $\mathrm{N}_{1}=\left(\mu_{0}+\mathrm{p}_{02} \mu_{2}\right)$

$$
\text { MTFP }=\lim _{\mathrm{s} \rightarrow 0}\left\{1-\mathrm{TP}_{0}^{* *}(\mathrm{~s})\right\} / \mathrm{s}=\mathrm{N}_{1} / \mathrm{D}_{1}
$$

and $\mathrm{D}_{1}=\left(1-\mathrm{p}_{02} \mathrm{p}_{20}\right)$ 


\subsection{Availability of Primary Database Unit $\left(\mathrm{AP}_{\mathbf{0}}\right)$}

Let $\operatorname{AP}_{\mathrm{i}}(\mathrm{t})$, where $\mathrm{i} \in \mathrm{E}$, be the probability that the primary database unit is in upstate at instant $t$ given that the system entered regenerative state $i$ at $t=0$, and using arguments the theory of regenerative process, $\mathrm{AP}_{\mathrm{i}}(\mathrm{t})$ is seen to satisfy the following recursive relations

$\mathrm{AP}_{0}(\mathrm{t})=\mathrm{M}_{0}(\mathrm{t})+\mathrm{q}_{01}(\mathrm{t}) \subset \mathrm{AP}_{1}(\mathrm{t})+\mathrm{q}_{02}(\mathrm{t}) \subset \mathrm{AP}_{2}(\mathrm{t})+\mathrm{q}_{04}(\mathrm{t}) \subset \mathrm{AP}_{4}(\mathrm{t})+\mathrm{q}_{05}(\mathrm{t}) \subset \mathrm{AP}_{5}(\mathrm{t})$

$\mathrm{AP}_{1}(\mathrm{t})=\mathrm{q}_{10}(\mathrm{t}) \subset \mathrm{AP}_{0}(\mathrm{t})+\mathrm{q}_{17}^{(6)}(\mathrm{t}) \subset \mathrm{AP}_{7}(\mathrm{t})$

$\mathrm{AP}_{2}(\mathrm{t})=\mathrm{M}_{2}(\mathrm{t})+\mathrm{q}_{20}(\mathrm{t})\left(\mathrm{AP}_{0}(\mathrm{t})+\mathrm{q}_{21}^{(3)}(\mathrm{t}) \subset \mathrm{AP}_{1}(\mathrm{t})\right.$

$\mathrm{AP}_{4}(\mathrm{t})=\mathrm{q}_{41}(\mathrm{t}) \mathbb{C} \mathrm{AP}_{1}(\mathrm{t})$

$\mathrm{AP}_{5}(\mathrm{t})=\mathrm{q}_{51}(\mathrm{t}) \subset \mathrm{AP}_{1}(\mathrm{t})$

$\mathrm{AP}_{7}(\mathrm{t})=\mathrm{M}_{7}(\mathrm{t})+\mathrm{q}_{70}(\mathrm{t}) \mathbb{C} \mathrm{AP}_{0}(\mathrm{t})+\mathrm{q}_{71}^{(8)}(\mathrm{t}) \subset \mathrm{AP}_{1}(\mathrm{t})$

where, $\mathrm{M}_{0}(\mathrm{t})=\mathrm{e}^{-(\lambda+\alpha) \mathrm{t}}, \quad \mathrm{M}_{2}(\mathrm{t})=\mathrm{e}^{-\lambda \mathrm{t}} \overline{\mathrm{G}_{1}}(\mathrm{t})$

$\mathrm{M}_{7}(\mathrm{t})=\mathrm{e}^{-\lambda \mathrm{t}} \overline{\mathrm{G}}(\mathrm{t}) \quad(58-66)$

Taking Laplace transform of the above equations and solving them for $\operatorname{AP}_{0}{ }^{*}(\mathrm{~s}), \mathrm{We}$ obtain

$$
\mathrm{AP}_{0}^{* *}(\mathrm{~s})=\mathrm{N}_{2}(\mathrm{~s}) / \mathrm{D}_{2}(\mathrm{~s})
$$

Where, $\mathrm{N}_{2}(\mathrm{~s})=\left(1-\mathrm{q}_{17}^{(6) *}(\mathrm{~s}) \mathrm{q}_{71}^{(8) *}(\mathrm{~s})\right)\left(\mathrm{q}_{02}{ }^{*}(\mathrm{~s}) \mathrm{M}_{2}{ }^{*}(\mathrm{~s})+\mathrm{M}_{0}{ }^{*}(\mathrm{~s})\right)$

$$
+\mathrm{q}_{17}^{(6) *}(\mathrm{~s})\left(\mathrm{q}_{01}{ }^{*}(\mathrm{~s})+\mathrm{q}_{05}{ }^{*}(\mathrm{~s}) \mathrm{q}_{51}{ }^{*}(\mathrm{~s})+\mathrm{q}_{04}{ }^{*}(\mathrm{~s}) \mathrm{q}_{41}{ }^{*}(\mathrm{~s})+\mathrm{q}_{02}{ }^{*}(\mathrm{~s}) \mathrm{q}_{21}{ }^{*}(\mathrm{~s})\right) \mathrm{M}_{7}{ }^{*}(\mathrm{~s})
$$

and $\mathrm{D}_{2}(\mathrm{~s})=\left(1-\mathrm{q}_{02}{ }^{*}(\mathrm{~s}) \mathrm{q}_{20}{ }^{*}(\mathrm{~s})\right)\left(1-\mathrm{q}_{17}^{(6) *}(\mathrm{~s}) \mathrm{q}_{71}^{(8) *}(\mathrm{~s})\right)-\mathrm{q}_{04}{ }^{*}(\mathrm{~s}) \mathrm{q}_{41}{ }^{*}(\mathrm{~s})\left(\mathrm{q}_{10}{ }^{*}(\mathrm{~s})\right.$

$\left.+\mathrm{q}_{70}{ }^{*}(\mathrm{~s}) \mathrm{q}_{17}^{(6) *}(\mathrm{~s})\right)-\mathrm{q}_{10}{ }^{*}(\mathrm{~s})\left(\mathrm{q}_{02}{ }^{*}(\mathrm{~s}) \mathrm{q}_{21}^{(3) *}(\mathrm{~s})+\mathrm{q}_{01}{ }^{*}(\mathrm{~s})+\mathrm{q}_{05}{ }^{*}(\mathrm{~s}) \mathrm{q}_{51}{ }^{*}(\mathrm{~s})\right)$

$-\mathrm{q}_{17}^{(6)}{ }^{*}(\mathrm{~s})\left(\mathrm{q}_{05}{ }^{*}(\mathrm{~s}) \mathrm{q}_{51}{ }^{*}(\mathrm{~s}) \mathrm{q}_{70}{ }^{*}(\mathrm{~s})+\mathrm{q}_{01}{ }^{*}(\mathrm{~s}) \mathrm{q}_{70}{ }^{*}(\mathrm{~s})+\mathrm{q}_{21}^{(3)}{ }^{*}(\mathrm{~s}) \mathrm{q}_{02}{ }^{*}(\mathrm{~s}) \mathrm{q}_{70}{ }^{*}(\mathrm{~s})\right)$

In steady-state the availability of primary database unit, is given by

$$
\mathrm{AP}_{0}=\lim _{\mathrm{t} \rightarrow \infty} \mathrm{AP}_{0}(\mathrm{t})=\lim _{\mathrm{s} \rightarrow 0} \mathrm{sAP}_{0}^{*}(\mathrm{~s})=\mathrm{N}_{2} / \mathrm{D}_{2}
$$

where, $\mathrm{N}_{2}=\left(1-\mathrm{p}_{17}^{(6)} \mathrm{p}_{71}^{(8)}\right)\left(\mu_{1}+\mathrm{p}_{02} \mu_{2}\right)+\left(1-\mathrm{p}_{02} \mathrm{p}_{20}\right) \mathrm{p}_{17}^{(6)} \mu_{7}$

and $\quad \mathrm{D}_{2}=\left(1-\mathrm{p}_{17}^{(6)} \mathrm{p}_{71}^{(8)}\right)\left(\mu_{0}+\mathrm{p}_{04} \mu_{4}+\mathrm{p}_{05} \mu_{5}+\mathrm{p}_{02} \mathrm{~K}_{2}\right)+\left(1-\mathrm{p}_{02} \mathrm{p}_{20}\right)\left(1+\mathrm{p}_{17}^{(6)}\right) \mathrm{K}_{1} \quad(70-72)$ Proceeding in the similar manner and employing the arguments used for regenerative process, the other measures of system effectiveness are:

Expected time for which standby database unit worked as primary database unit $\left(\mathrm{S}_{0}\right)$ $=\mathrm{N}_{3} / \mathrm{D}_{2}$

Expected time for updating the redo log files in standby database unit $\left(A U_{0}\right)=N_{4} / D_{2}$ Expected time for creating redo log files in standby database unit $\left(A_{0}\right)=N_{5} / D_{2}$

Expected time for repairing primary database unit $\left(\mathrm{BP}_{0}\right)=\mathrm{N}_{6} / \mathrm{D}_{2}$

Expected time for repairing standby database unit $\left(\mathrm{BH}_{0}\right)=\mathrm{N}_{7} / \mathrm{D}_{2}$

Expected number of visits by DBA $\left(\mathrm{V}_{0}\right)=\mathrm{N}_{8} / \mathrm{D}_{2}$

where, $\mathrm{N}_{3}=\left(1-\mathrm{p}_{02} \mathrm{p}_{20}\right) \mu_{1} ; \quad \mathrm{N}_{4}=\left(1-\mathrm{p}_{17}^{(6)} \mathrm{p}_{71}^{(8)}\right) \mathrm{p}_{04} \mu_{4}$

$\mathrm{N}_{5}=\left(1-\mathrm{p}_{17}^{(6)} \mathrm{p}_{71}^{(8)}\right) \mathrm{p}_{05} \mu_{5} \quad ; \quad \mathrm{N}_{6}=\left(1-\mathrm{p}_{02} \mathrm{p}_{20}\right)\left(\mathrm{K}_{1}+\mathrm{p}_{17}^{(6)} \mathrm{K}_{1}\right)$

$\mathrm{N}_{7}=\left(1-\mathrm{p}_{17}^{(6)} \mathrm{p}_{71}^{(8)}\right) \mathrm{p}_{02} \mathrm{~K}_{2} \quad ; \quad \mathrm{N}_{8}=\left(1-\mathrm{p}_{17}^{(6)} \mathrm{p}_{71}^{(8)}\right)$

and $\mathrm{D}_{2}$ is already specified in equation (72).

On the basis of the above measures, the cost-benefit analysis can be carried out as in the following section. 


\section{Cost-Benefit Analysis}

Needless to say, that the profit is most important aspect for a company/firm/organization using any type of system and hence, it is significant to carry out cost-benefit analysis for the system under consideration.

The profit is excess of revenue over the various costs involved and hence profit function takes the form

$$
P(t)=\text { Expected revenue in }(0, t]-\text { Expected total cost in }(0, t]
$$

For the model discussed in the present paper, the expected profit per unit time incurred to the system, in steady-state, is given by

Profit $(\mathrm{P})=($ Revenue generated by the system $)-($ Cost incurred when the secondary database is used as primary database + cost for updating the redo log files in standby database unit + cost for creating the redo log files in standby database unit + cost for which DBA is busy for repairing primary database unit + cost for which DBA is busy for repairing standby database unit + cost per visit of $\mathrm{DBA}+$ cost of Initial Installation)

$$
\text { i.e. } \mathrm{P}=\left(\mathrm{C}_{0} \mathrm{AP}_{0}\right)-\left(\mathrm{C}_{1} \mathrm{~S}_{0}+\mathrm{C}_{2} \mathrm{AU}_{0}+\mathrm{C}_{3} \mathrm{AC}_{0}+\mathrm{C}_{4} \mathrm{BP}_{0}+\mathrm{C}_{5} \mathrm{BH}_{0}+\mathrm{C}_{6} \mathrm{~V}_{0}+2 \mathrm{CI}\right)
$$

where, $\mathrm{C}_{0}=$ Revenue per unit uptime

$\mathrm{C}_{1}=$ Cost per unit time for which standby database unit worked as primary database unit

$\mathrm{C}_{2}=$ Cost per unit time for updating the redo log files in standby database unit

$\mathrm{C}_{3}=$ Cost per unit time for creating the redo log files in standby database unit

$\mathrm{C}_{4}=$ Cost per unit time for which DBA is busy for repairing primary database unit

$\mathrm{C}_{5}=$ Cost per unit time for which DBA is busy for repairing standby database unit

$\mathrm{C}_{6}=$ Cost per visit of DBA

$\mathrm{CI}=$ Cost per unit time of Initial Installation

Now, one may be interested in knowing as to how the MTSF, availability of primary database unit and profit are affected with changes in various rates/cost/revenue. The authors have made an attempt to find such effects by performing various numerical calculations as done in the following section.

\section{Numerical Calculations, Results and Discussion}

\subsection{Input Variables}

For numerical calculations we consider repair times, time for updating and creating redo $\log$ files follows exponential distribution i.e.

$$
g(t)=\eta e^{-\eta t}, g_{1}(t)=\alpha_{1} e^{-\alpha_{1} t}, h_{1}(t)=\gamma_{1} e^{-\gamma_{1} t} \text { and } h_{2}(t)=\gamma_{2} e^{-\gamma_{2} t}
$$

The estimates of various probabilities, rates and costs for primary database unit as well as for standby database unit on the basis of the data collected are given as follows:

Probability that standby unit is in synchronous with primary unit on the failure of primary database unit $\left(\mathrm{p}_{1}\right)=0.1628$

Probability that redo log files are not updated in standby database unit on the failure of primary database unit $\left(\mathrm{p}_{2}\right)=0.0465$

Probability that redo $\log$ files are not created in standby database unit on the failure of primary database unit $\left(\mathrm{p}_{3}\right)=0.7907$

Constant failure rate of primary database unit $(\lambda)=0.00205$ per $\mathrm{hr}$

Constant repair rate of primary database unit $(\eta)=0.6529$ per $\mathrm{hr}$

Constant failure rate of standby database unit $(\alpha)=0.00087 \mathrm{per} \mathrm{hr}$

Constant repair rate of standby database unit $\left(\alpha_{1}\right)=0.8533 \mathrm{per} \mathrm{hr}$

Cost per unit time for which DBA is busy for repairing primary database unit $\left(C_{4}\right)=7326 ₹$ 
Cost per unit time for which DBA is busy for repairing standby database unit $\left(\mathrm{C}_{5}\right)=8750 ₹$ The values of above mentioned input variables have been taken as fixed as obtained from the collected data. However, for some parameters/variable, the data were not available and hence their values have been assumed as mentioned in the sub-sections 6.3 to 6.5.

\subsection{Output Variables}

The output variables here are various measures of system effectiveness including MTSF, Availability of primary database unit and Profit function. Results of the effects of various input variables on the output variables have been obtained and have been shown in the following sub-sections:

\subsection{Effect of Rate $\left(\gamma_{1}\right)$ on MTSF and Availability $\left(\mathbf{A P}_{\mathbf{0}}\right)$ for Different Values of $\operatorname{Rate}\left(\gamma_{2}\right)$}

MTSF and steady-state availability of primary database $\left(\mathrm{AP}_{0}\right)$ are calculated on varying the rate $\left(\gamma_{1}\right)$ for different values of rate $\left(\gamma_{2}\right)$.The results are shown in Table 1 .

Table 1: Values of MTSF and Availability $\left(\mathrm{AP}_{0}\right)$ w.r.t. Rate $\left(\gamma_{1}\right)$ for Different Values of Rate $\left(\gamma_{2}\right)$

\begin{tabular}{ccccccc}
\hline$\gamma_{1}$ & \multicolumn{3}{c}{ MTSF $(\mathrm{In} \mathrm{hrs})$} & \multicolumn{3}{c}{ Availability $\left(\mathrm{AP}_{0}\right)$} \\
\hline & $\gamma_{2}=\mathbf{2 . 9 8}$ & $\boldsymbol{\gamma}_{2}=\mathbf{2 . 9}$ & $\gamma_{2}=\mathbf{3}$ & $\gamma_{2}=\mathbf{2 . 9 8}$ & $\gamma_{2}=\mathbf{2 . 9}$ & $\gamma_{2}=\mathbf{3}$ \\
$\mathbf{5}$ & 118178.5 & 118178.3 & 118178.1 & 0.996309 & 0.996311 & 0.996313 \\
$\mathbf{6}$ & 118178.1 & 118177.9 & 118177.7 & 0.996312 & 0.996314 & 0.996316 \\
$\mathbf{7}$ & 118177.9 & 118177.7 & 118177.4 & 0.996314 & 0.996316 & 0.996318 \\
$\mathbf{8}$ & 118177.7 & 118177.5 & 118177.2 & 0.996316 & 0.996318 & 0.99632 \\
$\mathbf{9}$ & 118177.5 & 118177.3 & 118177.1 & 0.996317 & 0.996319 & 0.996321 \\
$\mathbf{1 0}$ & 118177.4 & 118177.2 & 118177 & 0.996318 & 0.99632 & 0.996322 \\
\hline
\end{tabular}

It is observed that

(i). MTSF decreases with the increase in the values of rate $\left(\gamma_{1}\right)$ and it has lower values for higher values of rate $\left(\gamma_{2}\right)$.

(ii). Availability of primary database $\left(\mathrm{AP}_{0}\right)$ increases with the increase in the rate $\left(\gamma_{1}\right)$ and has higher values for higher values of rate $\left(\gamma_{2}\right)$.

\subsection{Effect of Revenue $\left(C_{0}\right)$ on Profit $(P)$ for Different Values of Cost $\left(C_{1}\right)$}

Behavior of profit $(\mathrm{P})$ with respect to revenue $\left(\mathrm{C}_{0}\right)$ per unit uptime for different values of cost $\left(\mathrm{C}_{1}\right)$ per unit time for which standby database worked as primary unit is shown in Figure 3. Profit increases with increase in the revenue and has higher values for lower values of cost $\left(\mathrm{C}_{1}\right)$.

Moreover, for $\gamma_{1}=12, \gamma_{2}=3, \mathrm{C}_{2}=50, \mathrm{C}_{3}=150, \mathrm{C}_{6}=100, \mathrm{CI}=5$, it is also observed that

i. For $\mathrm{C}_{1}=50$, the profit is positive, zero or negative according to $\mathrm{C}_{0}>$ or $=$ or $<$ 42.55. Hence for $C_{1}=50$, the revenue should be more than 42.55 to get the profit. 


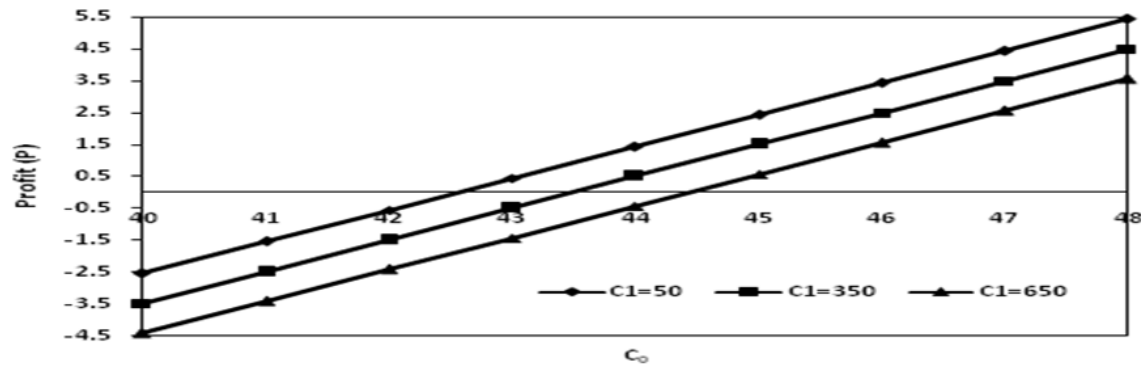

Figure 3: Profit (P) Versus Revenue $\left(C_{0}\right)$ for Different Values of Cost $\left(C_{1}\right)$

ii. For $\mathrm{C}_{1}=350$, the profit is positive, zero or negative according to $\mathrm{C}_{0}>$ or $=$ or $<$ 43.49. Hence for $C_{1}=350$, the revenue should be more than 43.49 to get the profit.

iii. For $\mathrm{C}_{1}=650$, the profit is positive, zero or negative according to $\mathrm{C}_{0}>$ or $=$ or $<$ 44.43. Hence for $C_{1}=650$, the revenue should be more than 44.43 to get the profit.

\subsection{Effect of Cost $\left(C_{3}\right)$ on Profit (P) for Different Values of Cost $\left(C_{6}\right)$}

Profit $(\mathrm{P})$ decreases with increase in the cost $\left(\mathrm{C}_{3}\right)$ per unit time for creating the redo $\log$ files (archiving) and has higher values for lower value of cost $\left(\mathrm{C}_{6}\right)$ per visit of the DBA. Also, when $\gamma_{1}=12, \gamma_{2}=3, \mathrm{C}_{0}=43, \mathrm{C}_{1}=50 \mathrm{C}_{2}=50, \mathrm{CI}=5$, it is interpreted from Figure 4 that

i. For $\mathrm{C}_{6}=100$, the profit is positive, zero or negative according to $\mathrm{C}_{3}<$ or $=$ or $>$ 980.6. Hence for $\mathrm{C}_{6}=100$, the cost for creating the redo $\log$ files should not be more than 980.6 to get the profit.

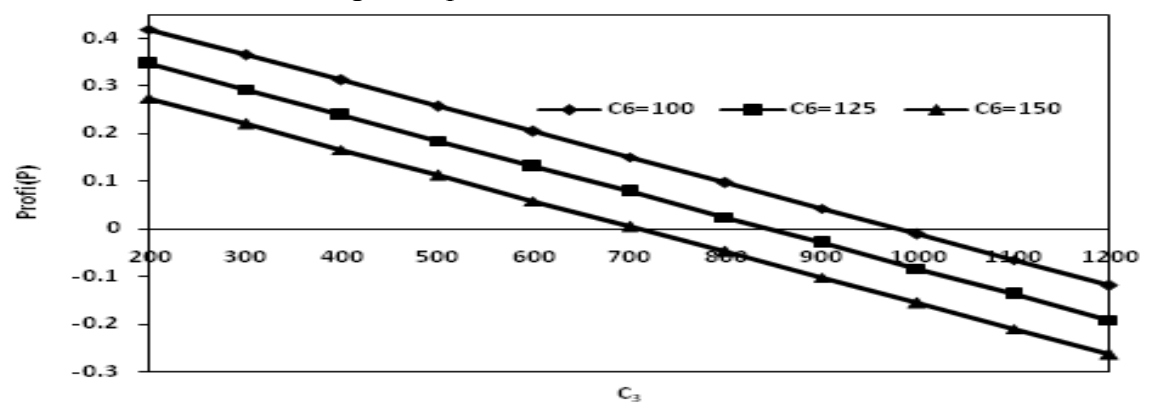

Figure 4: Profit (P) Versus Revenue $\left(C_{3}\right)$ for Different Values of Cost $\left(C_{6}\right)$

ii. For $\mathrm{C}_{6}=125$, the profit is positive, zero or negative according to $\mathrm{C}_{3}<$ or $=$ or $>845.49$. Hence for $\mathrm{C}_{6}=125$, the cost for creating the redo log files should not be more than 845.49 to get the profit.

iii. For $\mathrm{C}_{6}=150$, the profit is positive, zero or negative according to $\mathrm{C}_{3}<$ or $=$ or $>710.38$. Hence for $\mathrm{C}_{6}=150$, the cost for creating the redo log files should not be more than 710.38 to get the profit.

On the basis of the analysis done above, we have come to the following conclusion. 


\section{Conclusion}

In this paper, we have successfully done the stochastic modeling of two unit hot standby database system. Expressions for various measures of system effectiveness are obtained. Cost/revenue always remains a considerable and vital factor while developing a reliability model for a particular system and hence bounds (lower/upper) for revenue and the cost per unit time for creating the redo log files have been obtained. These ensure that whether the system is functioning in profit or running in loss. Bounds for many other parameters as per the specified requirement of the users can also be obtained in the similar manner.

Acknowledgement: The authors are grateful to the reviewers/editors for their valuable comments and suggestions.

\section{References}

[1]. El-Said, K.M., and M.S. El-sherbeny. Profit Analysis of a Two Unit Cold Standby System with Preventive Maintenance and Random Change in Units. Journal of Mathematics and Statistics, 2005; 1(1): 71-77.

[2]. Parashar, B., and G. Taneja. Reliability and Profit Evaluation of a Plc Hot Standby System Based on a Master-Slave Concept and Two Types of Repair Facilities. IEEE Transactions on Reliability, 2007; 56(3): 534-539.

[3]. El-Damcese, M.A. Analysis of Warm Standby Systems Subject to Common-Cause Failures with Time Varying Failure and Repair Rates. Applied Mathematical Sciences, 2009; 3(18): 853-860.

[4]. Beith, B., L. Hong, and J. Sarkar. A Standby System with Two Repair Persons under Arbitrary Life-and Repair Times. Mathematical and Computer Modelling, 2010; 51:756-767.

[5]. Shakuntla, S., A.K. Lal, S.S. Bhatia, and J.Singh. Reliability Analysis of Polytube Industry Using Supplementary Variable Technique. Applied Mathematics and Computation, 2011; 218: 3981- 3992.

[6]. Rizwan, S.M., N. Padmavathi, A. Pal, and G. Taneja. Reliability Analysis of a Seven Unit Desalination Plant with Shutdown During Winter Season and Repair/Maintenance on FCFS Basis.International Journal of Performability Engineering, 2013; 9(5): 523-528.

[7]. Manocha, A., and G.Taneja.Stochastic Analysis of a Two-Unit Cold Standby System with Arbitrary Distribution for Life, Repair and Waiting Times. International Journal of Performability Engineering, 2015; 11(3): 293-299.

[8]. Kuo,C.-C., and J.-C. Ke. Comparative Analysis of Standby Systems with Unreliable Server and Switching Failure. Reliabiliy Engineering and System Safety, 2016; 145: 74-82.

[9]. Kumar, R., and S. Batra. Cost-Benefit and Performance Analysis of a Stochastic Model on Printed Boards Manufacturing Process. International Journal of Mathematics in Operational Research, 2016; 8(4): 490-508.

[10]. Singh, S., R. Rishi, G. Taneja, and A. Manocha. Reliability and Availability Analysis of Database System with Standby Unit Provided by the System Provider. International Journal of Soft Computing and Engineering, 2013; 3(2): 235- 237.

Amit Manocha is working as an Assistant Professor in Department of Mathematics at T.I.T.S, Bhiwani, Haryana, India. His area of interest is Reliability Modelling.

Gulshan Taneja is currently working as a Professor in Department of Mathematics, M.D. University, Rohtak, Haryana, India. His areas of interest are Reliability Modelling, Queuing Theory and Optimization.

Sukhvir Singh is working as an Associate Professor in Department of Computer Science at N.C.C.E., Panipat, Haryana, India. His areas of interest are Software Engineering, Software Reliability, Data Mining and Networking. 